\title{
Closed Reduction and Lateral Percutaneous Pin Fixation for Displaced Supracondylar Humerus Fractures in Children
}

\author{
Khaled Edrees Abd_El-Rahman ${ }^{1}$, Mohammad Hamed Fahmy ${ }^{1}$, Mohammad Abd_El-Fattah \\ Sebaei $^{1}$, Mahmoud Ali Ali Abo Hasan ${ }^{1}$ * \\ ${ }^{l}$ orthopedic surgery department, Faculty of Medicine, Zagazig University.
}

\section{*Corresponding author: Mahmoud Ali Ali Abo Hasan dr.mahmod89@gmail.com}

$\begin{array}{ll}\text { Submit Date } & 28-3-2019 \\ \text { Revise Date } & 12-4-2019 \\ \text { Accept Date } & 14-4-2019\end{array}$

\section{A B S T R A C T}

Background: Lateral percutaneous pin fixation of Supracondylar humerus fracture (SCHF) is usually performed after accepted closed reduction. The aim of this study was to achieve fracture stability, maintained reduction and satisfactory results while minimizing the risk of iatrogenic ulnar nerve injury. Patients and methods: Twenty patients with extension Gartland kind II and III SCHFs treated by closed reduction and lateral transcutaneous pin fixation from December 2016 to December 2017 were enrolled in single center, prospective, observational, randomized controlled clinical trial. Postoperative immobilization was with an above elbow back splint and an arm sling. On days 1, 7, 14, and 21; obtained radiographs were evaluated. Results: according Flynn's criteria; all cases had satisfactory functional and cosmetic results. Only one case of a local infection was reported and treated with antibiotic therapy. Currently, all patients could perform daily activities. Discussion: lateral pinning technique had achieved fracture stability, maintenance of reduction and alignment, satisfactory functional and anatomical results in the form of a cosmetically accepted upper limb with normal range of movement while minimizing the risk of neurovascular complications as iatrogenic ulnar nerve injury in displaced SCHFs in children. Conclusion: With anatomic reduction and stable fixation, CRPP with lateral-entry

$\mathrm{K}$-wires fixation of paediatric SCHFs is comparable to the traditional crosswire fixation in terms of the steadiness, however superior in terms of ulnar nerve safety, thence giving glorious results. Level of evidence: $\mathrm{V}$ prospective randomized controlled study.

Key words: Lateral Pinning, SCHF, Ulnar N injury

\section{INTRODUCTION}

P ediatric around elbow represent close all paediatric orthopedical (SCHF) could be a common fracture accounting for regarding seventy five and sixty five. $4 \%$ of all upper limb fractures.[1] Mostly; these fractures are due to a fall from height (e.g., swings) but to less extent can occur after a fall on the ground level (i.e., bicycle).[2] The occurrence rate increases steadily in the early five years of life to peak at the age of 5-7 years. They are one among the greatest sources of significant issues and treatment argument in childhood fractures. Several techniques for transcutaneous fixation of those fractures are outlined so as to attenuate the chance of ulnar nerve injury. [1] 
Fall onto an extended hand that puts an extension load on the arm is that the distal fragment displaces posteriorly in over $95 \%$ of cases which represents extension type. On the other hand, the flexion type is caused by strong impact on the posterior surface of the humerus when the elbow is flexed (3\%). [2]

Of extension variety of SCHFs, regarding one third shows very little or no displacement and in these, the treatment is easy. The rest is related to variable degrees of major displacement. There's no disceptation regardi ng the management of undisplaced fractures however style of strategies of treatment for displaced SCHFs. [3]

The standard treatment for Gartland1.2. displaced varieties II \& III extension SCHFs in kids is closed reduction and transcutaneous pinning (CRPP). [4] But, the optimum

methodology of transcutaneous pin fixation varies among authors. Swenson, Casiano and Flynn et al. used 2 crossed pins, one medially introduced and another laterally. Arino et al. used 2 lateral pins. Though crossed mediallateral pin fixation provides enhanced biomechanical stability, it's the danger of induced ulnar1.3. nerve injury from the medial- placed pin. [5]

\section{PATIENT AND METHOD}

\section{Patients}

Twenty patients who satisfied the inclusion and exclusion criteria were enrolled in the study from December 2016 to December 2017. Demographic data including age, sex, side affected mechanism of injury and grading of fracture were recorded and compared for all patients. Mean follow-up was 5.575 months. (Table 1) reports the main demographic. On days 1, 7, 14, and 21; we obtained antero -posterior and lateral radiographs of the elbow. Inclusion criteria were age between 2 and 12 years, unilateral fracture, displaced extension Gartland types II and III, presenting within 72 hours after the injury, with neither associated injury in the same limb, nor previous fracture in the same limb. Exclusion criteria were age less than 2 years or greater than 12 years, bilateral fracture, flexion type, undisplaced Gartland the typical mechanism of such injury. Then,

type I, associated injury in the same limb, open fracture, floating elbow, unsatisfactory closed reduction requiring open reduction, and associated neurovascular injury requiring surgical exploration.

Written informed consents were obtained from all participants and the study has been approved by the research ethical committee of Faculty of Medicine, Zagazig University (IRB\#: 3233/18-12-2016). Our work has been carried out in accordance with The Code of Ethics of the World Medical Association (Declaration of Helsinki) for studies involving humans.

\section{Treatment sequence}

In the operating room, closed reduction was done, under general anaesthesia. Transcutaneous pin fixation was then performed and directed with image intensifier according to a uniform standardized technique; lateral pinning in all patients. Postoperative immobilisation was with an above elbow back splint. A simple arm sling was applied. Immobilisation was used for about 28 days. The pins were removed at outpatient clinic.

\section{Evaluating of the radiographic outcomes}

Pre- and post-operative radiographic assessment of the fracture is mandatory (Fig. 1a\&b). The anteroposterior radiographic analysis parameters were assessed on the Baumann's angle [6] and reduction of the lateral and medial columns of the distal humerus. Inadequate reduction was thought-about if a stepoff over two millimetres was apparent on every column. On the lateral radiographic read, the lateral capitellohumeral angle [7] was evaluated and reconstruction of the sandglass look was calculable. A step-off over a pair of millimeter on

the sandglass was reportable as an inadequate reduction. Secondary displacement was thought of if over $10^{\circ}$ distinction in Baumann's angle and/or the lateral capitellohumeral angle [8] and/or more than a pair of millimeter difference within the lateral and/or medial columns on the antero- 
posterior view and/or on the sandglass on the lateral view (Fig. 1c\&d). All radiographic assessments were assessed by an orthopedist.

\subsection{Statistical analysis}

Collected data were coded, analyzed and fed to the computer using IBM SPSS software package (Version 20) for windows. The appropriate statistical tests were used and the level of significance was considered at 5\% $(\mathrm{P} \leq 0.05)$.

\section{RESULTS}

The radiographic and clinical analysis proved our hypothesis. According Flynn's criteria; $45 \%$ of cases had excellent cosmotic results where $55 \%$ of cases had good results. All cases had satisfactory functional results as $35 \%$ of cases had excellent results, $60 \%$ had good results and only one case $(5 \%)$ had fair result (Tables 2, 3). This study encounteredcomplication was one case had a local infection (Figure 2) treated with antibiotic therapy. To date, no patients have needed reoperation; there are no reports of serious complications, iatrogenic ulnar nerve injury, or cases of elbow stiffness. No compartment syndrome were encountered pre- and postoperatively. Currently, all patients may perform daily activities.

Table [1]: Demographic and surgical data.

\begin{tabular}{|c|c|}
\hline Data & Mean $\pm \mathrm{SD}$ or $\mathbf{N}$ \\
\hline - $\quad$ Age, (years) & 5.65 \\
\hline - Sex & $F=6 / M=14$ \\
\hline - $\quad$ Side of fracture & $R=8 / L=12$ \\
\hline - Gartland type & II, N = 8/IIIa, N = 8/IIIb = 4 \\
\hline
\end{tabular}

M: male; F: female; R: right; L: left; SD: standard deviation; N: number of patients.

Table [2]: Functional results; range of motion (ROM).

\begin{tabular}{|l|l|l|}
\hline Results & Number & $\%$ \\
\hline Satisfactory & 20 & 100 \\
- Excellent & 7 & 35 \\
- Good & 12 & 60 \\
- Fair & 1 & 5 \\
\hline Unsatisfactory & 0 & 0 \\
\hline
\end{tabular}

Table [3]: Cosmetic results:

\begin{tabular}{|l|l|l|}
\hline Results & Number & $\%$ \\
\hline Satisfactory & 20 & 100 \\
- Excellent & 9 & 45 \\
- Good & 11 & 55 \\
- Fair & 0 & 0 \\
\hline Unsatisfactory & 0 & 0 \\
\hline
\end{tabular}




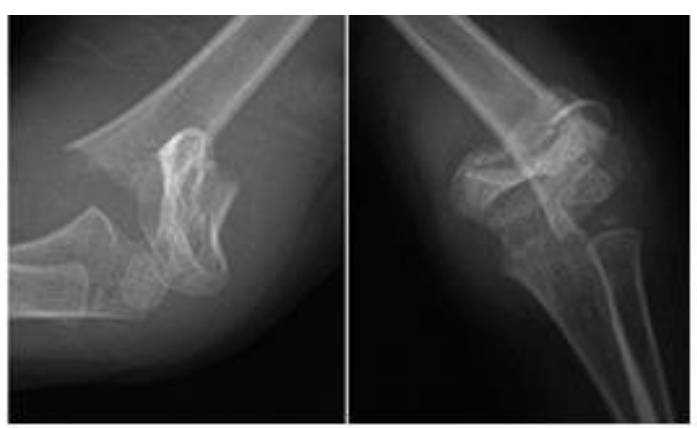

Figure la: Pre-operative $x$-ray.

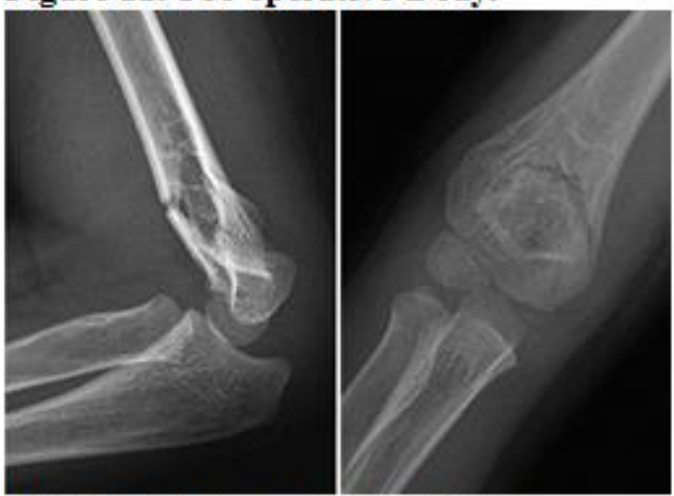

Figure lc: 4 weeks post-operative.

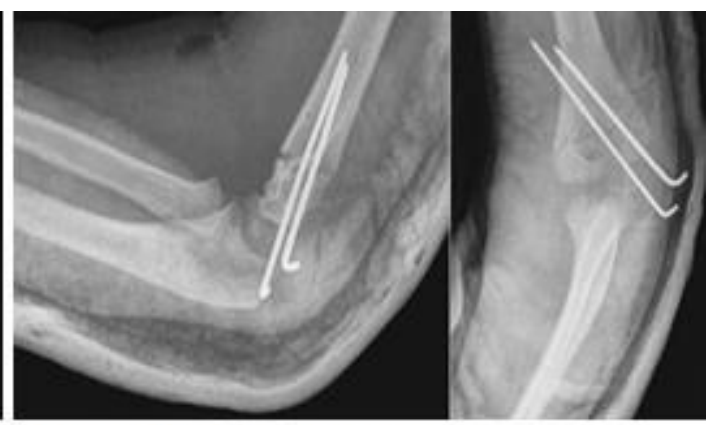

Figure lb: Post-operative $x$-ray

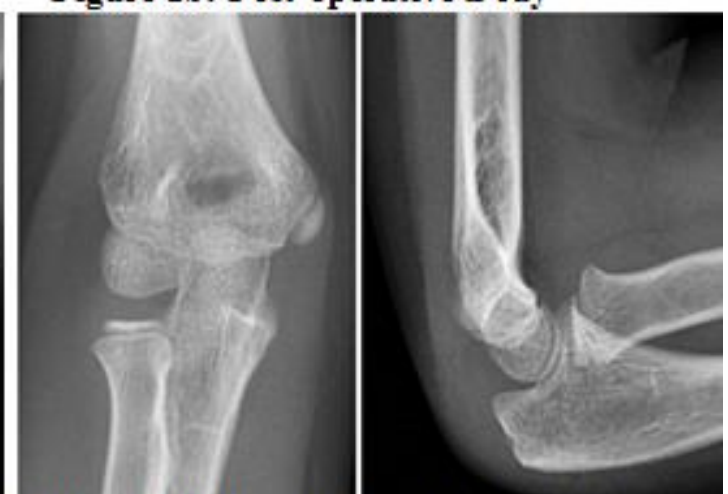

Figure ld: 9 months post-operative

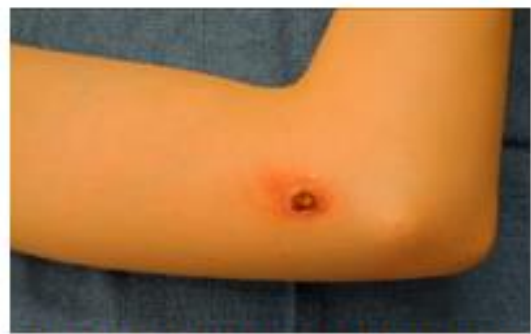

Figure 2: Pin tract infection treated with oral antibiotic

\section{DISCUSSION}

A bio-mechanical compare of all pin types were performed by Lee et al. [9] in extension, varus, valgus, internal rotation and external rotation employing an artificial bone model. Divergent configuration laterally to forestall nerve palsy had enough stability however in rotation testing; this type of configuration had less stability than different configurations. During this study divergent pins provided a lot of stability than crossed pin in extension, and varus testing.

Reynolds and Jackson [10] prompt that stability depends on 3 factors that are below the management of the surgeon: the dimensions of the pin, the space between the pins on the road of the fracture, the pins being within the bone on either side of the fracture.

According to Skaggs et al. [11] the engagement of the adequate bone within the proximal and distal fragment is additional vital. Most separation of the pins at the fracture line is incredibly vital for the bio-mechanical stability. Iatrogenic nervus ulnaris injury is often betterknown complication within the treatment of CRPP of displaced SCHF with the utilization of medial pin. [12] Though most of the nervus ulnaris injuries recover spontaneously at intervals four and 6 months, permanent injury has been reported within the literature. [13]

As a result we have a tendency to report that our results are winning with the appliance of $\mathrm{CR}$ and lateral PP. The most goal of the treatment of displaced paediatric SCHFs is to get associate anatomic reduction. This reduction ought to be supported by a fixation with a decent stability and less morbidity.

In our study, the pins were removed after three to four weeks. It was found that it takes (on average) one month for complete ROM at elbow to return to pre-fracture ROM. Our 
finding was comparable to that of Wang et al. [14] who concluded that it takes about 5 weeks after removal of cast, to restore original ROM at the elbow joint.

The authors of a large study [15], of 345 patients, concluded that fixation of both typeII and type-III pediatric SCHFs with only lateral pins provides adequate fixation while avoiding iatrogenic injury to the ulnar nerve.

In our study, all fractures, irrespective of the degree of instability, were treated with success with lateral- entry pins alone. Postoperatively, the largest change in the Baumann angle was only $11^{\circ}$.

We were much more likely to use three lateral-entry pins for type III SCHFs than we were for type-II fractures, and we recommend employing three lateral-entry pins if there is any concern about fracture stability or pin position after the first two pins have been placed.

Before pin placement, the surgeon may use subjective parameters to determine whether to place three lateral-entry pins. Such parameters may involve a critical displaced type-III fracture, a great patient, and/or an older patient. On stress testing instability would be an ultimate indication to place a $3^{\text {rd }}$ lateral pin.

A recent biomechanical search elucidated that 2 divergent lateral-entry pins gift further stability in extension loading than do two crossed pins. [16] On the idea of those results, we have a tendency to believe that it's a very important issue for biomechanical stability is greatest separation of the pins at the fracture. It's been shown that 3 lateral pins offer additional torsional stability than do 2 lateral pins. [17]

Gottschalk H. et al [18] declared specific commendations for pin placing through dividing the inter-epicondylar zone into four zones. The space between the pins at the fracture site has been reported as an important risk factor for fixation fail [19]. The four anatomic zone systems provides a simple and reproducible guide for pin placement that achieves pin spread and may help treating surgeons to reduce surgeon-related mistake in pin spread. Regrettably, comminuted medial column has a harmful impact on the varus bending strength of the fixation.

\section{CONCLUSION}

Closed reduction and percutaneous pinning with lateral-entry K-wires technique of paediatric SCHFs is similar to the conventional cross-wire technique in terms of the fracture stability, but superior in terms of ulnar nerve safety, hence giving excellent results. With anatomic reduction and stable Fixation, most kids come to full activity with glorious outcomes and no longrun sequelae from this injury.

\section{Declaration of interest}

The authors report no conflicts of interest. The authors alone are responsible for the content and writing of the paper.

Funding information: None declared

\section{REFERENCES}

1. Leitch KK, Kay RM, Femino JD, Tolo VT, Storer SK, Skaggs DL. Treatment of multidirectionally unstable supracondylar humeral fractures in children. A modified Gartland type-IV fracture. The Journal of bone and joint surgery. American volume. May 2006;88(5):980-985.

2. Shannon FJ MP, Chacko J, D'souza LG. 'Dorgan's' percutaneous lateral cross-wiring of supracondylar fractures of the humerous in children. . Journal of pediatric orthopedics. Part B. 2004;24:376-379.

3. Douira-Khomsi W SM, Louati H, Jlalia Z, Ghachem MB, Bellagha I. Multi slice computed tomography approach in the assessment of supracondylar humeral fractures in children Acta Orthop Belg. 2012;78(4):458-464.

4. Hamdi A PP, Louati $\mathrm{H}$, et al. Biomechanical analysis of lateral pin placements for pediatric supracondylar humerus fractures. . J Pediatr Orthop. 2010; 30:135-139.

5. Maity A. SD, and Roy D.S. A prospective randomised, controlled clinical trial comparing medial and lateral entry pinning with lateral entry pinning for percutaneous fixation of displaced extension type supracondylar fractures of the humerus in children. Journal of Orthopaedic Surgery and Research. 2012:7:6.

6. Fan JR, Xu YW, Zheng Y, You JY. [Emergency closed reduction and percutaneous Kirschner wire fixation for treatment of Gartland type II-III supracondylar fractures of the humerus in children]. Zhongguo gu shang = China journal of orthopaedics and traumatology. May 2015;28(5):464-467.

7. Wu W, Li X, Shi Q, Dai S, Tan W, Hu C. [Minimally invasive treatment of Gartland type III humerus supracondylar fracture in children]. Nan 
fang yi ke da xue xue bao = Journal of Southern Medical University. Aug 2014;34(9):1351-1354.

8. Han QL, Wang YH, Liu F. Comparison of complications and results of early versus delayed surgery for Gartland type III supracondylar humeral fractures in pediatric patients. Orthopaedic surgery. Nov 2011;3(4):242-246.

9. Zenios M, Ramachandran M, Milne B, Little D, Smith N. Intraoperative stability testing of lateralentry pin fixation of pediatric supracondylar humeral fractures. Journal of Pediatric Orthopaedics. 2007;27(6):695-702.

10. Reynolds RA, Jackson H. Concept of treatment in supracondylar humeral fractures. Injury. 2005;36(1):S51-S56.

11. Skaggs DL, Cluck MW, Mostofi A, Flynn JM, Kay RM. Lateral-entry pin fixation in the management of supracondylar fractures in children. JBJS. 2004;86(4):702-707.

12. Devnani A. Late presentation of supracondylar fracture of the humerus in children. Clinical Orthopaedics and Related Research®. 2005;431:36-41.

13. Dekker A, Krijnen P, Schipper I. Results of crossed versus lateral entry K-wire fixation of displaced pediatric supracondylar humeral fractures: A systematic review and meta-analysis. Injury. 2016;47(11):2391-2398.

14. Wang Y-L, Chang W-N, Hsu C-J, Sun S-F, Wang J-L, Wong C-Y. The recovery of elbow range of motion after treatment of supracondylar and lateral condylar fractures of the distal humerus in children. Journal of orthopaedic trauma. 2009;23(2):120-125.

15. Skaggs DL, Hale JM, Bassett J, Kaminsky C, Kay RM, Tolo VT. Operative treatment of supracondylar fractures of the humerus in children: the consequences of pin placement. JBJS. 2001;83(5):735-740.

16. Pradhan A, Hennrikus W, Pace G, Armstrong A, Lewis G. Increased pin diameter improves torsional stability in supracondylar humerus fractures: an experimental study. Journal of children's orthopaedics. 2016;10(2):163-167.

17. Silva M, Knutsen AR, Kalma JJ, et al. Biomechanical testing of pin configurations in supracondylar humeral fractures: the effect of medial column comminution. Journal of orthopaedic trauma. 2013;27(5):275-280.

18. Gottschalk H. Ph. SD, Glaser D., Doan J., Edmonds E. W., and Schlechter J. . Biomechanical Analysis of Pin Placement for Pediatric Supracondylar Humerus Fractures: Does Starting Point, Pin Size, and Number Matter? J Pediatr Orthop B. 2012;32:445-451.

19. Skaggs DL, Sankar WN, Albrektson J, Vaishnav S, Choi PD, Kay RM. How safe is the operative treatment of Gartland type 2 supracondylar humerus fractures in children? Journal of pediatric orthopedics. Mar 2008;28(2):139-141.

To Cite This Article: Abd_El-Rahman KE, Fahmy MH, Sebaei MA, Abo Hasan MA. Closed Reduction and Lateral Percutaneous Pin Fixation for Displaced Supracondylar Humerus Fractures in Children .Zumj 2020; 27(2) : doi 10.21608/zumj.2019.10859.1150 